\title{
The modelling of buoyancy driven flow in bubble columns
}

\section{G. M. Cartland Glover and S. C. Generalis*}

School of Engineering and Applied Science, Division of Chemical Engineering and Applied Chemistry, Aston University, Birmingham, B4 7ET U. K. Tel: +44 1213593611 ext 4707, Fax: $+441213594094$

*Corresponding Author E-mail Address: s.c.generalis@ aston.ac.uk

\begin{abstract}
Using the analogy between lateral convection of heat and the two-phase flow in bubble columns, alternative turbulence modelling methods were analysed. The k- $\varepsilon$ turbulence and Reynolds stress models were used to predict the buoyant motion of fluids where a density difference arises due to the introduction of heat or a discrete phase. A large height to width aspect ratio cavity was employed in the transport of heat and it was shown that the Reynolds stress model with the use of velocity profiles including the laminar flow solution resulted in turbulent vortices developing. The turbulence models were then applied to the simulation of gas-liquid flow for a 5:1 height to width aspect ratio bubble column. In the case of a gas superficial velocity of $0.02 \mathrm{~m} \mathrm{~s}^{-1}$ it was determined that employing the Reynolds stress model yielded the most realistic simulation results.
\end{abstract}

Keywords: Two-Phase Flow, Bubble Columns, Computational Fluid Dynamics, Mixture Models, Turbulent Reynolds Stresses, k- $\varepsilon$ Turbulence, Thermal Convection 


\section{Introduction}

Bubble columns are seen as good tools for the reaction and transfer of mass, but design procedures reduce the effectiveness of reactor design [1]. Understanding of the complexity of the fluid dynamics in bubble columns is important due to their application in the chemical and bioprocess industries. Many parameters control the flow of the fluid phases through bubble columns, where the relative buoyancy of the discrete phase is the major driving force for the flow regime. Other factors that impact on the complex flow phenomena include the coalescence and dispersion of bubbles, surface tension, viscosity and pressure effects. The value of these parameters can influence the size, shape and volume fraction of the bubbly gas phase [1-2].

In an effort to enhance the performance of equipment over the past two decades, many attempts have been made to develop accurate and workable predictive models of the flow regimes that are present. However, many of these models are one-dimensional and do not account for the threedimensional transient turbulent interactions that increase the complexity of any solution attempted [2]. Computational fluid dynamics is a tool that can be used to demonstrate the influence of the multi-dimensional transport of discrete phases on the hydrodynamics. Nevertheless, there are limitations to the effectiveness of the mathematical models employed when averaging the gas and liquid phases to specific particle sizes and fluid properties.

Over the last decade modelling techniques applied to multiphase flow in bubble columns have shown improvement in representing the flow regimes (Torvik and Svendsen [3-4], Sokolichin and Eigenberger [5-9], Lapin and Luebbert [7], [9], Delnoij et al. [11] and Ranade [12]). The 
two-fluid model represents both phases as pseudo-continua with continuity of mass and momentum equations independently predicting the motion of each phase and has been rigorously examined with flows in two-dimensional bubble columns [3-9] and [11]. The mixture model employs a transport equation (to predict the discrete phase volume fraction) along with the continuity of mass and momentum equations that treat the phases as a pseudo-continuous mixture of both the continuous and discrete phases [13-16]. An alternative method of modelling the motion of the gas bubbles in a batch liquid column is discrete particle tracking [7][10-11], where individual bubble motion is predicted in a Lagrangian frame of reference. The particle tracking method is computationally intensive, even for low gas phase fractions, as the motion of each bubble/particle is considered in the calculation of multiphase flow phenomena. The two-fluid and mixture model methods can predict gas phase motion more efficiently, but at a reduced accuracy as the influence of bubble rotation and wake effects are generally ignored [2].

The discrete phase models we present were derived from earlier simulations of a 5:1 bubble column for both two and three dimensions cases [13-16], which in turn were based on the experimental investigations of Degaleesan et al [13]. The dynamics of gas-liquid mixture were analysed along with consideration of discrete particle motion and initial developments in pseudocontinua representations of the solid phase fraction [13-16]. Comparing vector fields for the experimental [17] and numerical investigations [3] [15] in Figs. 1-3, the vortices observed in Fig. 1 do not correspond to the flow structures depicted in axisymmetric (Fig. 2) and plane fields (Fig. 3a.), when solving gas-liquid motion with k- $\varepsilon$ the two-dimensional turbulence model [22]. The corresponding structures are only observed within the fully three-dimensional simulation where the corresponding vector fields are depicted in Fig. 3b [15]. Restricting the complexity of the 
flow to two-dimensions therefore greatly reduces the reproducibility of the experimentally observed eddies, particularly when k- $\varepsilon$ turbulence models are employed. A reduction in the computational demand was observed when ignoring the third-dimension [15]. The aim of the present project is to assist in the implementation of the computationally intensive two and threephase flow models when solved with the transport of turbulent Reynolds stresses. Including all these models increases the time required to obtain a flow solution and would therefore significantly increase the time required to obtain a three-dimensional flow solution. Therefore, we considered meshes that are either axisymmetric or plane in form. The use of the axisymmetric mesh is limited as only the radius of the column is considered, whereas the plane mesh is a slice over the whole diameter of the column. Using the whole column diameter enables the modelling of the column diameter non-axisymmetric scaled vortices. Restricting the domain to just the radius of the column limits the modelling of these vortices, therefore the plane mesh was employed here. We have chosen to investigate under homogeneous flow conditions so that the influence of coalescence and break-up is negligible [2]. Therefore, a fixed bubble size of 5 $\mathrm{mm}$ was used with a superficial gas velocity of $0.02 \mathrm{~m} \mathrm{~s}^{-1}[17]$.

Heat transport has been long established in the modelling of turbulent flows particularly when simulating natural convection in cavities with large height to diameter ratios [21-22]. The convection of heat across the width of the mesh provides an excellent example of how to simulate the turbulent interactions in buoyancy driven flows. Applying the analogy, between lateral multiphase flow in bubble columns and lateral convection [23] it would seem of interest to attempt to model the transport of the discrete phase using the same techniques that are applied when modelling the buoyant motion of air between two infinite plates at differing temperatures. To employ this technique effectively, it would be wise to test the capacity of the solver employed 
(Fluent [28-29]) by simulating lateral convection of heat in a long vertical channel. The investigations of Chait and Korpela [22] provide the basis for the simulation of buoyancy driven flows where heat causes local differences in the fluid density.

\section{Mathematical Models}

\section{Energy Transport}

The thermal transport equation (1) has the general form of a transport equation with time dependent and the non-linear velocity terms on the left hand side. On the right had side is the temperature gradient and the velocity coupling term. These last two terms are intrinsic to the accurate prediction of the structure of both the velocity and temperature fields and how each of the variables influences the other. Along with the energy transport equation, the conservation of mass (2) and momentum (3) are used to predict and check the pressure and velocity fields. The fluid density considered was temperature-dependent and was calculated by using the Boussinesq approximation (5), which was then applied to the transport equations ((1)-(3)). The coefficient of thermal expansion, $\beta$, is an average value for the temperature range considered.

\section{Algebraic Slip Mixture Model [13][28-29]}

The investigations of Zuber, Findlay, Ishii and Mishima provide the physical and theoretical basis for the application of a continuum mixture approach to the simulation of multiphase flow [24-26]. Considering the discrete and continuous phases as a pseudo-continuous mixture, a 
single continuity equation (9) and a single momentum equation (10) were employed to assess mixture phase transport. To predict the mixture phase composition a volume fraction equation for the discrete phase (11), a mixture density (12) and a mixture viscosity (13) must be employed to characterise gas-liquid or solid-liquid interactions.

Each phase has distinct interactions that influence the transport of one phase through the other. This was characterised by the use of mass-averaged (14), drift (15) and slip (16) velocities. The slip or relative velocity was obtained by averaging a combined momentum equation for the discrete phase and the mixture according to the principles of local equilibrium and Favre averaging. The assumptions made, in the averaging procedure, were that the pressure was the same for all phases and that only viscous drag influences particle motion leading to fluctuating form of slip velocity. A constitutive equation was then employed to account for the fluctuating terms to further simplify the relative velocity [27].

Frictional effects depend on the flow regime (equations (17)). This is considered when modelling such flows [24-26]. The Reynolds number, equation (18), was based on the particle diameter that serves as the characteristic dimension. The regimes vary according to discrete particle size, the volume has a critical influence on the driving forces fraction and the distribution of particle sizes. Predicting flow phenomena in the heterogeneous regime increases the complexity of the description of the mixture phase, as different bubble sizes are prevalent. Therefore as mentioned above, in order to simplify the models employed we concentrate our flow predictions on the homogeneous regime, where a single bubble size was assumed. 


\section{Modified Scalar Equation Mixture Model}

The scalar transport model can be used to model the transport of any parameter where the volume fraction of a phase, heat or the influence of electromagnetism [28-29] are some examples. The scalar equation (19) employed here models the transport of a pseudo-continuous discrete phase in conjunction with the basic continuity and momentum equations. We note here that the solver specifies all the terms on the left hand side of equation (19). To produce a relevant solution, a diffusion coefficient was used, $\Gamma$, and this was defined as $0.1 \mathrm{~m}^{2} \mathrm{~s}^{-1}$, though correlations could be used to predict the dispersion of each phase [27]. To depict the transport of the discrete phase source terms are applied to the right hand side of the scalar equation (19). The last term on the right hand side of (19) is the deviatoric stress tensor to include the influence of turbulence on the bubble plume in a similar manner to the energy equation (1) by using the analogy to thermal convection. The third term is the inter-phase interaction term that is calculated by the drift velocity. The second term on the right hand side of (19) is the convective flux of the discrete phase. We note that there are two convective fluxes with one for the mixture phase and that the scalar equation (which predicts the volume fraction) is different to the volume fraction formulation used in the algebraic slip mixture model [13][28-29]. Comparing both volume fraction equations, equations (11) and (19), it is apparent that the diffusive flux term and the deviatoric stress tensor are not found in (11). The continuity of mass and momentum equations that are solved with equation (19) have the same form as the continuity equations, equations (9) and (10), used in the algebraic slip mixture model [13][28-29]. The drift velocity was also calculated in a similar manner using equations (12)-(16). The mixture viscosity was 
predicted with the aid of equations (20)-(21) and this differs from the algebraic slip mixture model [13][28-29], which only employs (13).

\section{Transport of Turbulence}

The k- $\varepsilon$ turbulence equations are used to depict the transport of energy between large and small vortices in the velocity field. The transport of turbulent energy was modelled through the use of a pair of coupled transport equations (22) and (23) that describes the generation of energy due to motion (conversion from one source i.e. due to density difference) in one equation (22) and dissipation of that energy in the other (23). This effectively characterises the growth and evolution of vortices caused by some form energy input be that agitation from heat, another fluid or the motion of a solid object.

The exact Reynolds stress equation (28) is a more complex model and is simplified into several different equations to reduce the complexity of the formulation and to enable closure of the exact equation in the mathematical models [28-29]. This includes the use of both equations (22) and (23) plus the inclusion of the effects of buoyancy, pressure, pressure-strain and any rotation through equations (29)-(37).

In the prediction of the lateral convection of heat, it is beneficial to the numerical solution of the transport equations to split the flow into basic flow and secondary mean flow quantities [21-22]. The basic flow quantity was determined from a known profile that was obtained under laminar flow conditions (38). The secondary mean flow is determined by taking an $\mathrm{x}-\mathrm{y}$ average of the Navier-Stokes equation and this then represents the effect of the Reynolds Stresses. Using such a 
profile is relevant to multiphase flow that is based on the density difference driving force, therefore, exploiting the analogy with natural convection [23]. The velocity profiles for the lateral convection of heat and the gas-liquid flow cases are in the form of equations (39) and (40). The basic profile for the gas-liquid flow (40) was obtained from the reported experimental velocity profiles of Degaleesan et al. [13][17-19] and the lateral heat convection profile (39) was the laminar flow profile of Chait and Korpela [22]. Reynolds stresses therefore are intrinsically important in attempting to capture the turbulence effects in the fluid flow that arises from the differences in density.

\section{Model Parameters}

\section{Boundary Conditions and Physical Properties}

The meshed domains are two-dimensional planes with height to width ratios of either 50:1 (in an attempt to model a vertical cavity of infinite extent) or 5:1 (that corresponds to previous investigations [13-19]). The high aspect ratio mesh contains 5000 cells in a plane 500 cells high by 10 cells wide (where each cell is $0.1 \mathrm{~m}$ high $\times 0.1 \mathrm{~m}$ wide). The lower aspect ratio mesh contains 2000 cells (with the ratio 100:20 cells, where each cell is $0.01 \mathrm{~m}$ high $\times 0.01 \mathrm{~m}$ wide). Four walls surround the large aspect ratio mesh to which temperature conditions are applied. For the small height to width ratio mesh, velocity-inlet and pressure-inlet conditions are applied to the bottom and the top of the mesh respectively, with the remaining boundaries being treated as walls. The velocity-inlet condition is only applied to $80 \%$ of the base of the column that mimics a multi-orifice plate distributor and the pressure-inlet was used to represent the liquid surface. 
The conditions applied to the inlet boundaries include the volume fraction, the pressure and the inlet velocity of the discrete phase.

The physical properties of the fluids simulated include the density, the viscosity, the specific heat capacity, the thermal expansion coefficient and the thermal conductivity of each of the fluids. The fluid phase density and viscosity are defined as $1.225 \mathrm{~kg} \mathrm{~m}^{-3}$ and $1.7894 * 10^{-5} \mathrm{~kg} \mathrm{~m}^{-1} \mathrm{~s}^{-1}$ for air, $998.2 \mathrm{~kg} \mathrm{~m}^{-3}$ and $1.003 * 10^{-3} \mathrm{~kg} \mathrm{~m}^{-1} \mathrm{~s}^{-1}$ for water. The diameter for the air bubbles was $5 \mathrm{~mm}$ assuming that the form of the particles is spherical. The definition of the fluid phase for lateral convection of air required the specific heat capacity, the thermal expansion coefficient and the thermal conductivity to be defined as $1006.43 \mathrm{~J} \mathrm{~kg}^{-1} \mathrm{~K}^{-1}, 1.77 * 10^{-8} \mathrm{~K}^{-1}$ and $2.42 * 10^{-2} \mathrm{~W} \mathrm{~m}^{-1} \mathrm{~K}^{-1}$ respectively. The expansion coefficient was determined by using the Grashof number formulation, equation (6), assuming a value of 8500 [22]. This ensured strong non-linearity as the maximum Grashof number for which the basic flow exists is 8037 [22]. The Prandtl number, equation (41), for air under ambient conditions was assumed.

\section{Lateral Convection of Heat}

A cubic velocity profile is applied to the vertical velocity field, with an inflection point at the mid-point of the mesh in the horizontal direction (39). A temperature of $300 \mathrm{~K}$ was applied to the left wall and $310 \mathrm{~K}$ to the right wall and the fluid or air temperature was initialised as $305 \mathrm{~K}$.

To describe the influence of each turbulent flow modelling method three cases were implemented. These were thermal convection using the k- $\varepsilon$ turbulence model (A) or the Reynolds stresses model (B). The Reynolds stress model was also used with a profile for the velocity that 
was added to the solution (updating the velocity field) after each time-step (C). Each case was solved for 500 seconds of flow time, with a time-step size of 0.2 seconds to ensure that the correct flow phenomena were observed for validating the use of the energy and turbulence transport models in the software code [28]. All under-relaxation factors for the last ten cases were set to 1 except for the $\mathrm{k}-\varepsilon$ and Reynolds stress transport equations, which were defined as 0.1 .

\section{Gas-Liquid Transport}

Two models were employed in the prediction of the gas-liquid mixture, the algebraic slip (A1A3) mixture model [13] and the modified scalar equation (S1-S3) form of the mixture model. Three different applications of the turbulence models were applied to both mixture-modelling methods and comparisons with the experimental investigations of Degaleesan et al [17-19] were made. As for the lateral convection of heat, the three turbulence models applied to the fluid mixture include the k- $\varepsilon$ turbulence transport (A1 and S1), the Reynolds stress turbulence transport without applying the velocity profile (A2 and S2) and Reynolds stress turbulence transport with the updating of the laminar velocity profile after each time-step (A3 and S3).

For cases $\mathrm{S} 1$ to $\mathrm{S} 3$ the fraction of the gas phase at the inlet was defined as 0.6 for reasons of solution stability. The superficial gas velocity applied at the inlet was $2 \mathrm{~cm} \mathrm{~s}^{-1}$ (within the homogeneous flow regime) that is $3.125 \mathrm{~cm} \mathrm{~s}^{-1}$ if one considers that only $80 \%$ of the inlet diameter are concerned. Therefore, the mass flow-rate of the gas phase through the inlet was calculated to be $7.7^{*} 10^{-4} \mathrm{~kg} \mathrm{~s}^{-1}$. As only 16 of the 20 cells were used at the base (the gas phase inlet and the porosity or free surface area for the experimental distributor was $0.1 \%$ ), a flux 
through each cell was estimated to be 0.6 . The boundary condition for the gas fraction at the inlet velocity in cases A1 to A3 was 1 . The time step was 0.1 seconds (it was found that no difference in the solutions was obtained at a smaller time-step size). The flow fields were solved for 6000 steps or 600 seconds of flow time.

The discretization techniques applied to the discrete phase models include the use of the body force weighted scheme for pressure effects [28-29], the QUICK [30] scheme for the momentum equation and the SIMPLEC [31-34] algorithm that couples the velocity field to the pressure field. The volume fraction equation for the discrete phase was solved using a second order form of the UPWIND scheme [31-34] (due to a limitation in the solver). Under-relaxation factors were set at 0.1, $0.3,0.7$ for slip velocity, pressure, volume fraction and momentum equations respectively and all the remaining terms are set to 1 [13][15], except for the Reynolds stress turbulence model that has an under-relaxation factor of 0.1 .

\section{Results and Discussion}

\section{Lateral Convection of Heat}

Applying the energy equation to model the transport of heat in a 50:1 aspect ratio mesh for the three turbulence models resulted in velocity vector fields (Fig. 4) and stream function contours (Fig. 5). Only case $\mathrm{C}$ displays the expected vortices in Fig. 4 that are approximately two to three of the mesh widths in height. The stream-function contours for case $\mathrm{C}$ also display structures of the same scale in Fig. 5. The vector and contour plots for cases A and B do not show any of the 
flow phenomena that were observed in case C. The velocity for cases A and B was several orders of magnitude less than for case $\mathrm{C}$, resulting in the non-existent stream function contours observed in Fig. 5. Comparing the vector-fields and contours of stream function with earlier lateral convection models [22-23] it is apparent that only case C corresponds to the expected flow structure.

\section{Gas-Liquid Transport}

To characterise the gas-liquid flow phenomena modelled, time series of the vertical mixture velocity (Fig. 6), time-averaged profiles of vertical velocity (Fig. 7) and the volume fraction of the gas phase (Fig. 8) are presented. Field plots of velocity vectors and contours of the volume fraction of the gas phase depict the influence of each turbulence model on the mixture model employed (Fig. 9 for cases A1 to A3 and Fig. 10 for cases S1 to S3).

The time series of the vertical mixture velocity (Fig. 6) was recorded at half-second intervals from a point location on the column centreline at a height of $0.5 \mathrm{~m}$ above the base of the column for cases A1, S1, A2 and S2. For the A1 time series there is little or no change to the velocity, except for the initial 20-second period during which time the gas-liquid flow interactions and structures develop. This differs with the S1 time series, which displays a regular oscillation with a time-period of 25 seconds that first appears within 25 seconds of the gas flow starting. The time-period for the two-dimensional scalar equation case is almost 1.5 times greater than the regular oscillation that was observed for the three-dimensional simulation [15]. The increase in the time-period for the scalar equation model could be a result of ignoring the third dimension and therefore suppressing the motion of the vortices through the tangential axis of the column. 
Unsteady series for cases A2, S2, A3 and S3 were observed, where only the A2 and S2 curves are presented in Fig. 6. There is a difference between the A2 and S2 cases, as the regular oscillations that were observed for the A2 case do not occur for the S2 case. The time-period of the oscillation in the velocity for the A2 case was approximately 10 seconds and becomes regular after 30 seconds of time. The oscillations observed with the $\mathrm{S} 2$ case begin within 5 to 10 seconds of the flow being initialised. The time series for the A3 and S3 cases were little different from the A2 and S2 cases except that the velocity ranges were slightly higher. This was due to the influence of the velocity profile being updated after each time-step.

Profiles of the time-averaged vertical mixture velocity across the width of the mesh at a height of $0.5 \mathrm{~m}$ or 2.5 column widths are illustrated in Fig. 7. The curves for all the cases show parabolic forms, but only the S1 case is asymmetric. Most of the cases over-predict the velocities, particularly the $\mathrm{A} 2, \mathrm{~A} 3, \mathrm{~S} 1$ and $\mathrm{S} 3$ profiles. The $\mathrm{S} 2$ case is the most accurate case with profile that closely matches the experimental profile [17-19]. At the column centreline the S2 case was $0.011 \mathrm{~m} \mathrm{~s}^{-1}$ less than experimental profile [17-19] and the S3, A2 and A3 cases were 0.067, 0.096 and $0.145 \mathrm{~m} \mathrm{~s}^{-1}$ greater than the $\mathrm{S} 2$ case. At the column wall the $\mathrm{S} 2$ case was $0.02 \mathrm{~m} \mathrm{~s}^{-1}$ less than the experimental velocities. The increase in the velocities predicted at this point by the S3, A2 and A3 cases over the S2 case increased to $0.091,0.138$ and $0.216 \mathrm{~m} \mathrm{~s}^{-1}$ respectively.

Fig. 8 depicts the corresponding profiles for the volume fraction of the gas phase. The S2 and S3 profiles lay across the range of the experimental data with a flat, plug flow profile and correlate to hold-up profiles presented by Joshi [2], though the S2 case is $2 \%$ greater than the S3 case. The A2 and A3 profiles under-predict the volume fraction of the S2 case by $2 \%$ but with a 
parabolic form instead. Both models produce curves that are unlike experimental data, which have a discontinuous form that could be said to peak at $\sim 14 \%$ between $10.03 \mathrm{I}$ and $10.07 \mathrm{~m}$ from the column centre. Both the A1 and S1 cases differ from the cases solved with the Reynolds stress model, the A1 case has two distinct peaks either side of the column centreline and the S1 case is asymmetric with a peak on the right hand side of Fig. 8 that maps to the velocity profile.

Fig. 9 illustrates the vector and contour fields for the cases A1 to A3 and Fig. 10 displays the corresponding fields for cases S1 to S3. The vector fields for the A1 case are steady and consist of two large circulation patterns, with the bulk of the flow in the vertical direction. The influence that the steady vortices have on contours of the volume fraction of the gas phase with a steady gas plume can also be seen.

The flow pattern that arises from the scalar mixture model when solved with the S1 case is different, with unsteady elongated vortices on top of a large column diameter eddy at the base of the column. The vector field for the $\mathrm{S} 1$ case in Fig. 10 corresponds to phenomena observed in a cylindrical column model that are depicted in Fig. 3b [15] and the experimental fields in Fig.1 [13]. The influence of the vortices on the gas phase motion is shown through the meandering of the plume at the base of the column. The flow structures depicted by the field plots for the S1 case indicates why the profile is asymmetric with vortex pushing the main upward flow to the right side of the column.

Unsteady vortices of column diameter scale are observed for cases A2, A3, S2 and S3. The vector fields resemble the complex structures that were predicted in simulations by Sokolichin and Eigenberger [5-9]. The vortices in the S3 case are smaller than the vortices in the S1 and S2 
cases. The S3 field is comparable to the vector fields for A2 and A3 cases where the velocity 'updating' has little or no influence on the vector field. The S2 case displays elongated vortices that spread either side of the column diameter that are not stationary and grow and collapse as the gas phase is injected. The effect of the vector field for the Reynolds stress model application of the mixture model on the gas fraction is observed in the contour profiles for the volume fraction with meandering plumes. The S2 and S3 cases show a diffuse gas field with subtle influence of the vector field, whereas the A2 and A3 cases show a greater influence of the flow structure with eddies flicking the bubble plume from the left side of the column to right and vice versa. Note that the gas fraction increases in value just below the pressure inlet condition for the S2 and S3 cases. This is most probably due to the lack of bed expansion that occurs with having a fixed liquid surface.

\section{Conclusions}

The linear thermal transport problem for a large height to width ratio cavity indicates that turbulence models are required to obtain an unsteady flow structure with eddies that have a diameter equivalent to the mesh width. The only method that produced an unsteady flow structure was the Reynolds Stresses model where the 'updating' of vertical velocity profile took place after each time-step. The principles derived from this method of solving thermal convection in a cavity were then applied to gas phase transport through a liquid medium according to the analogy between buoyant thermal convection and multiphase flow in bubble columns [23]. Two modelling approaches testing the solution of the gas-phase transport equations were combined with three turbulence models to predict the unsteady motion of a 
continuum gas phase. Comparing the influence of different turbulence modelling methods on the gas phase transport, it was determined that the Reynolds stress model captures the unsteady nature of bubble columns through the variation in the velocity. The $\mathrm{S} 2$ was the most accurate model, with gas hold-up and velocity profiles that corresponded to the profiles presented by Sanyal et al. [13] Degaleesan et al. [17-19] and Joshi [2].

Further improvements to bubbly flow models could include predicting the effect of coalescence and break-up of bubbles on the overall gas phase by modelling the transport of multiple gas phases, where each volume fraction equation is solved for a specific bubble size. Other effects that have not been considered here and require further examination are comprehensively discussed in Joshi's review of bubble column investigations. These effects include the influence of multi-dimensional flows, bubble wakes, energy transport due to bubble motion [2].

\section{Acknowledgements}

We would like to acknowledge the support of Inco-Copernicus Grant number ERB IC15-CT980904 and Fluent Incorporated for enabling this work to be presented.

\section{Appendix A: Thermal Convection Equations}

Energy transport equation,

$$
\frac{\partial}{\partial t}(\rho E)+\frac{\partial}{\partial x_{i}}\left(u_{i}(\rho E+p)\right)=\frac{\partial}{\partial x_{i}}\left(\left(\kappa+\frac{c_{p} \mu_{t}}{\sigma_{t}}\right) \frac{\partial \theta}{\partial x_{i}}+u_{j}\left(\tau_{i j}\right)_{e f f}\right)+S_{h}
$$


conservation of mass equation,

$$
\frac{\partial \rho}{\partial t}+\frac{\partial}{\partial x_{i}}\left(\rho u_{i}\right)=S_{s}
$$

conservation of momentum equation,

$$
\frac{\partial}{\partial t}\left(\rho u_{i}\right)+\frac{\partial}{\partial x_{j}}\left(u_{i} u_{j}\right)=-\frac{\partial p}{\partial x_{i}}+\frac{\partial\left(\tau_{i j}\right)_{e f f}}{\partial x_{j}}-\rho_{0} \beta\left(T-T_{0}\right) g_{i}+F_{i}
$$

deviatoric stress tensor,

$$
\left(\tau_{\mathrm{ij}}\right)_{\mathrm{eff}}=\mu_{\mathrm{eff}}\left(\frac{\partial \mathrm{u}_{\mathrm{j}}}{\partial \mathrm{x}_{\mathrm{i}}}+\frac{\partial \mathrm{u}_{\mathrm{i}}}{\partial \mathrm{x}_{\mathrm{j}}}\right)-\frac{2}{3} \mu_{\mathrm{eff}} \frac{\partial \mathrm{u}_{\mathrm{i}}}{\partial \mathrm{x}_{\mathrm{i}}} \delta_{\mathrm{ij}}
$$

Boussinesq approximation,

$$
\rho=\rho_{0}(1-\beta \Delta T)
$$

Grashof Number,

$$
\mathrm{Gr}=\frac{\mathrm{g} \beta \Delta \mathrm{TL}^{3}}{v^{2}}
$$


characteristic velocity based on the Grashof number,

$$
\mathrm{U}=\frac{\mathrm{g} \beta \Delta \mathrm{TL}^{2}}{\mathrm{v}}
$$

temperature difference,

$$
\Delta \mathrm{T}=\mathrm{T}-\mathrm{T}_{0}
$$

Appendix B: Mixture Model Equations

Continuity equation for the mixture phase,

$$
\frac{\partial}{\partial t}\left(\rho_{m p}\right)+\frac{\partial}{\partial x_{i}}\left(\rho_{m p} u_{m p, i}\right)=0
$$

momentum equation for the mixture,

$$
\begin{aligned}
& \frac{\partial}{\partial t}\left(\rho_{m p} u_{m p, j}\right)+\frac{\partial}{\partial x_{i}}\left(\rho_{m p} u_{m p, i} u_{m p, j}\right)= \\
& -\frac{\partial p}{\partial x_{j}}+\frac{\partial}{\partial x_{j}} \mu_{m p}\left(\frac{\partial}{\partial x_{j}}\left(u_{m p, i}\right)+\frac{\partial}{\partial x_{i}}\left(u_{m p, j}\right)\right) \\
& +\rho_{m p} g_{j}+F_{j}+\frac{\partial}{\partial x_{i}} \sum_{q=1}^{n} \alpha_{q} \rho_{q} u_{D q, i} u_{D q, j}
\end{aligned}
$$


volume fraction equation for the mixture model,

$$
\frac{\partial}{\partial t}\left(\alpha_{q} \rho_{q}\right)+\frac{\partial}{\partial x_{i}}\left(\alpha_{q} \rho_{q} u_{m p, i}\right)=-\frac{\partial}{\partial x_{i}}\left(\alpha_{q} \rho_{q} u_{D q, i}\right)
$$

mixture density,

$$
\rho_{\mathrm{mp}}=\sum_{\mathrm{q}=1}^{\mathrm{n}} \alpha_{\mathrm{q}} \rho_{\mathrm{q}}
$$

mixture viscosity,

$$
\mu_{\mathrm{mp}}=\sum_{\mathrm{q}=1}^{\mathrm{n}} \alpha_{\mathrm{q}} \mu_{\mathrm{q}}
$$

mass averaged velocity,

$$
\overrightarrow{\mathrm{u}}_{\mathrm{mp}}=\frac{\sum_{\mathrm{q}=1}^{\mathrm{n}} \alpha_{\mathrm{q}} \rho_{\mathrm{q}} \overrightarrow{\mathrm{u}}_{\mathrm{q}}}{\rho_{\mathrm{mp}}}
$$

drift velocity,

$$
\overrightarrow{\mathrm{u}}_{\mathrm{Dq}}=\overrightarrow{\mathrm{u}}_{\mathrm{q}}-\overrightarrow{\mathrm{u}}_{\mathrm{mp}}=\overrightarrow{\mathrm{v}}_{\mathrm{q}, \mathrm{c}}-\frac{1}{\rho_{\mathrm{mp}}} \sum_{\mathrm{r}=1}^{\mathrm{n}-1} \alpha_{\mathrm{r}} \rho_{\mathrm{r}} \overrightarrow{\mathrm{v}}_{\mathrm{r}, \mathrm{c}}
$$


slip velocity equation,

$$
\vec{v}_{q, c}=\vec{u}_{q}-\vec{u}_{c}=\frac{d_{q}^{2}\left(\rho_{m p}-\rho_{q}\right)}{18 \mu_{c} f}\left(g_{j}-\frac{D \vec{u}_{m p}}{D t}\right)
$$

friction factor for the mixture model,

$$
\mathrm{f}=1+0.05 \operatorname{Re}^{0.687} \quad \operatorname{Re}<1000
$$

$$
\mathrm{f}=0.018 \mathrm{Re} \quad \operatorname{Re} \geq 1000
$$

particle Reynolds number,

$$
\operatorname{Re}=\frac{\mathrm{d}_{\mathrm{q}} \mathrm{u}_{\mathrm{mp}} \rho_{\mathrm{c}}}{\mu_{\mathrm{c}}}
$$

modified scalar equation,

$$
\begin{aligned}
& \frac{\partial \phi_{\mathrm{q}} \rho_{\mathrm{q}}}{\partial \mathrm{t}}+\frac{\partial}{\partial \mathrm{x}_{\mathrm{i}}}\left(\rho_{\mathrm{mp}} \mathrm{u}_{\mathrm{mp}, \mathrm{i}} \phi_{\mathrm{q}}-\Gamma \frac{\partial \phi_{\mathrm{q}}}{\partial \mathrm{x}_{\mathrm{i}}}\right)=\mathrm{S}_{\phi}+\nabla\left(\phi_{\mathrm{q}} \rho_{\mathrm{q}} \mathrm{u}_{\mathrm{mp}, \mathrm{i}}\right) \\
& +\nabla\left(\sum_{\mathrm{p}=1}^{\mathrm{n}} \phi_{\mathrm{q}} \rho_{\mathrm{q}} \mathrm{u}_{\mathrm{Dq}, \mathrm{i}}\right)+\nabla\left(\mu_{\mathrm{eff}}\left(\frac{\partial}{\partial \mathrm{x}_{\mathrm{j}}}\left(\mathrm{u}_{\mathrm{i}}\right)+\frac{\partial}{\partial \mathrm{x}_{\mathrm{i}}}\left(\mathrm{u}_{\mathrm{j}}\right)\right)\right)
\end{aligned}
$$


mixture viscosity,

$$
\mu_{\mathrm{mp}}=\mu_{\mathrm{c}}\left(1-\frac{\phi}{\phi_{\mathrm{qm}}}\right)^{-2.5 \phi_{\mathrm{qm}^{\mu}}{ }^{*}}
$$

gas phase $\mu^{*}$,

$\mu^{*}=\frac{\mu_{\mathrm{q}}+0.4 \mu_{\mathrm{c}}}{\mu_{\mathrm{q}}+\mu_{\mathrm{c}}}$

Appendix C: k- $\varepsilon$ Turbulence Transport Equations

turbulent kinetic energy transport equation,

$$
\rho \frac{\mathrm{Dk}}{\mathrm{Dt}}=\frac{\partial}{\partial \mathrm{x}_{\mathrm{i}}}\left[\left(\mu+\frac{\mu_{\mathrm{t}}}{\sigma_{\mathrm{k}}}\right) \frac{\partial \mathrm{k}}{\partial \mathrm{x}_{\mathrm{i}}}\right]+\mathrm{G}_{\mathrm{k}}+\mathrm{G}_{\mathrm{b}}-\rho \varepsilon
$$

rate of dissipation of energy from the turbulent flow,

$\rho \frac{\mathrm{D} \varepsilon}{\mathrm{Dt}}=\frac{\partial}{\partial \mathrm{x}_{\mathrm{i}}}\left(\mu+\frac{\mu_{\mathrm{t}}}{\sigma_{\varepsilon}}\right) \frac{\partial \varepsilon}{\partial \mathrm{x}_{\mathrm{i}}}+\mathrm{C}_{1 \varepsilon} \frac{\varepsilon}{\mathrm{k}}\left(\mathrm{G}_{\mathrm{k}}+\mathrm{C}_{3 \varepsilon} \mathrm{G}_{\mathrm{b}}\right)-\mathrm{C}_{2 \varepsilon} \frac{\varepsilon^{2}}{\mathrm{k}}$ 
turbulent viscosity formulation,

$\mu_{\mathrm{t}}=\rho \mathrm{C}_{\mu} \frac{\mathrm{k}^{2}}{\varepsilon}$

total derivative for the turbulent kinetic energy,

$$
\frac{\mathrm{Dk}}{\mathrm{Dt}}=\frac{\partial \mathrm{k}}{\partial \mathrm{t}}+\frac{\partial \mathrm{ku}}{\partial \mathrm{x}_{\mathrm{i}}}
$$

total derivative for the rate of dissipation of energy from the turbulent flow,

$$
\frac{\mathrm{D} \varepsilon}{\mathrm{Dt}}=\frac{\partial \varepsilon}{\partial \mathrm{t}}+\frac{\partial \varepsilon \mathrm{u}}{\partial \mathrm{x}_{\mathrm{i}}}
$$

constant that determines the orientation buoyant shear layers,

$$
\mathrm{C}_{3 \varepsilon}=\tanh \left|\frac{\mathrm{u}_{\mathrm{j}}}{\mathrm{u}_{\mathrm{i}}}\right|
$$


exact transport equation for the transport of Reynolds Stresses,

$$
\begin{aligned}
& \frac{\partial}{\partial t}\left(\rho \overline{u_{i} u_{j}}\right)+\frac{\partial}{\partial x_{1}}\left(\rho U_{1} \overline{u_{i} u_{j}}\right)= \\
& \left.-\frac{\partial}{\partial x_{1}}\left[\rho \overline{u_{i} u_{j} u_{1}}+\overline{p\left(\delta_{1 j} u_{i}+\delta_{i l} u_{j}\right.}\right)\right] \\
& +\frac{\partial}{\partial x_{1}}\left[\mu \frac{\partial}{\partial x_{1}}\left(\overline{u_{i} u_{j}}\right)\right]-\rho\left(\overline{u_{i} u_{1}} \frac{\partial U_{j}}{\partial x_{1}}+\overline{u_{j} u_{1}} \frac{\partial U_{i}}{\partial x_{1}}\right) \\
& -\rho \beta\left(g_{i} \overline{u_{j} \theta}+g_{j} \overline{u_{i} \theta}\right)+p\left(\frac{\partial u_{i}}{\partial x_{j}}+\frac{\partial u_{j}}{\partial x_{i}}\right) \\
& -2 \mu \frac{\partial u_{i}}{\partial x_{1}} \frac{\partial u_{j}}{\partial x_{1}}-2 \rho \Omega_{1}\left(\overline{u_{j} u_{m} \varepsilon_{i k m}}+\overline{u_{i} u_{m} \varepsilon_{j k m}}\right)
\end{aligned}
$$

turbulent diffusive transport,

$$
\frac{\partial}{\partial x_{1}}\left[\rho \overline{u_{i} u_{j} u_{1}}+\bar{p}\left(\delta_{1 j} u_{i}+\delta_{i l} u_{j}\right)\right]=\frac{\partial}{\partial x_{1}}\left(\frac{\mu_{t}}{\sigma_{k}} \frac{\partial}{\partial x_{1}}\left(\overline{u_{i} u_{j}}\right)\right)
$$

buoyancy effects,

$$
B_{i j}=\rho \beta\left(g_{i} \overline{u_{j} \theta}+g_{j} \overline{u_{i} \theta}\right)=\beta \frac{\mu_{t}}{\sigma_{t}}\left(g_{i} \frac{\partial \rho}{\partial x_{j}}+g_{j} \frac{\partial \rho}{\partial x_{i}}\right)
$$


stress production,

$$
P_{i j}=\rho\left(\overline{u_{i} u_{1}} \frac{\partial U_{j}}{\partial x_{1}}+\overline{u_{j} u_{1}} \frac{\partial U_{i}}{\partial x_{1}}\right)
$$

system rotation effects,

$$
R_{i j}=2 \rho \Omega_{1}\left(\overline{u_{j} u_{m} \varepsilon_{i k m}}+\overline{u_{i} u_{m} \varepsilon_{j k m}}\right)
$$

pressure-strain term,

$$
\gamma_{i j}=p\left(\frac{\partial u_{i}}{\partial x_{j}}+\frac{\partial u_{j}}{\partial x_{i}}\right)
$$

decomposition of pressure-strain term,

$$
\gamma_{\mathrm{ij}}=\gamma_{\mathrm{ij}, 1}+\gamma_{\mathrm{ij}, 2}+\gamma_{\mathrm{ij}}^{\mathrm{W}}
$$

slow pressure-strain term,

$$
\gamma_{\mathrm{ij}, 1}=-\mathrm{C}_{1} \rho \frac{\varepsilon}{\mathrm{k}}\left[\overline{\mathrm{u}_{\mathrm{i}} \mathrm{u}_{\mathrm{j}}}-\frac{2}{3} \delta_{\mathrm{ij}} \mathrm{k}\right]
$$


rapid pressure-strain term,

$$
\gamma_{\mathrm{ij}, 2}=-\mathrm{C}_{2}\left[\begin{array}{l}
\left(\mathrm{P}_{\mathrm{ij}}+\mathrm{F}_{\mathrm{ij}}+\mathrm{B}_{\mathrm{ij}}+\frac{\partial}{\partial \mathrm{x}_{1}}\left(\rho \mathrm{U}_{1} \overline{\mathrm{u}_{\mathrm{i}} \mathrm{u}_{\mathrm{j}}}\right)\right. \\
+\frac{2}{3} \delta_{\mathrm{ij}}\left(\frac{1}{2} \mathrm{P}_{11}+\frac{1}{2} \mathrm{~B}_{11}-\frac{1}{2} \frac{\partial}{\partial \mathrm{x}_{1}}\left(\rho \mathrm{U}_{1} \overline{\mathrm{u}_{1} \mathrm{u}_{1}}\right)\right.
\end{array}\right]
$$

wall reflection term,

$$
\begin{aligned}
\gamma_{i j}^{w}= & C_{1}^{\prime} \frac{\varepsilon}{k}\left(\overline{u_{1} u_{m} n_{1} n_{m} \delta_{i j}-\frac{3}{2} \overline{u_{i} u_{1}} n_{j} n_{1}-\frac{3}{2} \overline{\left.u_{j} u_{1} n_{i} n_{1}\right)} \frac{k^{3 / 2}}{\left(C_{\mu}^{3 / 4} / \eta\right) \varepsilon W}}\right. \\
& C_{2}^{\prime}\left(\gamma_{1 m, 2} n_{1} n_{m} \delta_{i j}-\frac{3}{2} \gamma_{i l, 2} n_{j} n_{1}-\frac{3}{2} \gamma_{j 1,2} n_{i} n_{1}\right) \frac{k^{3 / 2}}{\left(C_{\mu}^{3 / 4} / \eta\right) \varepsilon W}
\end{aligned}
$$

the following equation separates the flow field variables into known and unknown values by referencing a known flow profile q'( $\left.\mathrm{x}_{\mathrm{i}}\right)$,

$$
q\left(x_{i}, x_{j}, t\right)=q^{\prime \prime}\left(x_{i}, x_{j}, t\right)+q^{\prime}\left(x_{i}\right)
$$

velocity profile for the lateral convection problem,

$$
\mathrm{u}=-\frac{\mathrm{x}_{\mathrm{i}}}{24}+\frac{\mathrm{x}_{\mathrm{i}}^{3}}{6}
$$


empirical velocity profile for air-water flow in a bubble column,

$$
\mathrm{u}=-0.9254 * \mathrm{x}_{\mathrm{i}}^{2}-0.1076 * \mathrm{x}_{\mathrm{i}}+0.1425
$$

Prandtl number,

$$
\sigma=\frac{v}{\kappa}
$$

\section{Nomenclature}

\section{General Symbols}

$$
\begin{array}{ll}
\mathrm{B} & =\text { buoyancy effect term from Reynolds stress model } \\
\mathrm{C} & =\text { coefficient } \\
\mathrm{C}_{1}^{\prime} & =\text { constant in the linear pressure-strain model, for the wall reflection term = } 0.5 \\
\mathrm{C}_{2}^{\prime} & =\text { constant in the linear pressure-strain model, for the wall reflection term = } 0.3 \\
\mathrm{c}_{\mathrm{p}} & =\text { specific heat capacity }\left(\mathrm{J} \mathrm{kg}^{-1} \mathrm{~K}^{-1}\right) \\
\mathrm{d} & =\text { particle diameter }(\mathrm{m}) \\
\mathrm{E} & =\text { enthalpy } \\
\mathrm{F} & =\text { external forces }\left(\mathrm{kg} \mathrm{m} \mathrm{s}{ }^{-2}\right) \\
\mathrm{f} & =\text { dimensionless friction factor }(-) \\
\mathrm{G} & =\text { generation of turbulent energy } \\
\mathrm{Gr} & =\text { Grashof Number }
\end{array}
$$




$$
\begin{aligned}
& \mathrm{g}=\text { acceleration due to gravity vector }\left(0-9.810 \mathrm{~m} \mathrm{~s}^{-2}\right) \\
& \mathrm{k} \quad=\text { kinetic energy }\left(\mathrm{m}^{2} \mathrm{~s}^{-2}\right) \\
& \mathrm{L} \quad=\text { characteristic length }(\mathrm{m}) \\
& \mathrm{n} \quad=\text { unit normal vector (where the subscript defines the direction of the vector) } \\
& \mathrm{P} \quad=\text { stress production term for the Reynolds Stress model } \\
& \mathrm{p} \quad=\text { pressure }\left(\mathrm{N} \mathrm{m}^{-2}\right) \\
& \mathrm{q} \quad=\text { variable (i.e. velocity) } \\
& \text { q’ = primary flow variable (i.e. velocity) } \\
& \text { q" = secondary flow variable (i.e. velocity) } \\
& \mathrm{R} \quad=\text { effect of system rotation of the Reynolds stress model } \\
& \text { Re } \quad=\text { Reynolds number (-) } \\
& \mathrm{S} \quad=\text { source term }\left(\mathrm{kg} \mathrm{m}^{-3} \mathrm{~s}^{-1}\right) \\
& \mathrm{t} \quad=\text { time }(\mathrm{s}) \\
& \mathrm{U} \quad=\text { mean velocity }\left(\mathrm{m} \mathrm{s}^{-1}\right) \\
& \mathrm{u} \quad=\text { velocity component }\left(\mathrm{m} \mathrm{s}^{-1}\right) \\
& \mathrm{v} \quad=\text { slip velocity component }\left(\mathrm{m} \mathrm{s}^{-1}\right) \\
& \mathrm{W}=\text { distance to the wall (m) } \\
& \mathrm{x}=\text { spatial co-ordinate }(\mathrm{m})
\end{aligned}
$$

\section{Mathematical Operators}

D $=$ total differential operator

tanh = hyperbolic tangent function

$\partial=$ partial differential operator 
$\nabla \quad=$ del operator

$\Delta \quad=$ difference between two quantities of a variable

$\Sigma \quad=$ summation

$\rightarrow \quad=$ vector form of variable (i.e. representing $\mathrm{i}, \mathrm{j}$ and $\mathrm{k}$ forms of the variable as a matrix)

- $\quad$ = bar denoting an averaged product

\section{Greek symbols}

$\alpha \quad=$ volume fraction $(-)$

$\beta \quad=$ coefficient of thermal expansion $\left(\mathrm{K}^{-1}\right)$

$\delta \quad=$ Kronecker symbol

$\varepsilon \quad=$ rate of dissipation of turbulent energy $\left(\mathrm{m}^{2} \mathrm{~s}^{-2}\right)$

$\phi \quad=$ scalar function variable, in this case representing the volume fraction of the discrete phase (-)

$\Gamma \quad=$ diffusion coefficient for the scalar function $=0.1 \mathrm{~m}^{2} \mathrm{~s}^{-1}$

$\gamma \quad=$ pressure strain $\left(\mathrm{N} \mathrm{m}^{-2} \mathrm{~s}^{-1}\right)$

$\eta \quad=$ constant for the linear pressure-strain model wall reflection term $=0.41$

$\theta \quad=$ temperature $(\mathrm{K})$

$\kappa=$ thermal conductivity $\left(\mathrm{W} \mathrm{m}^{-1} \mathrm{~K}^{-1}\right)$

$\mu \quad=$ dynamic viscosity $\left(\mathrm{kg} \mathrm{m}^{-1} \mathrm{~s}^{-1}\right)$

$v \quad=$ kinematic viscosity $\left(\mathrm{m}^{2} \mathrm{~s}^{-1}\right)$

$\rho \quad=$ density $\left(\mathrm{kg} \mathrm{m}^{-3}\right)$ 
$\sigma \quad=$ Prandtl number (for the kinetic energy equation is 1 for k- $\varepsilon$ turbulence transport or 0.82

for the Reynolds stresses and 1.3 for the dissipation rate)

$\tau \quad=$ deviatoric stress tensor

$\Omega \quad=$ mean rate of rotation tensor

\section{Subscripts and Superscripts}

$0 \quad=$ reference value for a physical property at a corresponding quantity for an associated variable i.e. density of fluid at a specific temperature

$1=$ constant for the linear pressure-strain model $=1.8$

$2=$ constant for the linear pressure-strain model $=0.6$

$1 \varepsilon \quad=$ constant for the turbulent dissipation of energy $=1.44$

$2 \varepsilon \quad=$ constant for the turbulent dissipation of energy $=1.92$

$3 \varepsilon \quad=$ constant for the turbulent dissipation of energy

$\mathrm{b} \quad=$ buoyancy

c $\quad=$ continuous phase

$\mathrm{Dq} \quad=$ drift velocity of the qth phase

eff = effective value in reference to the addition of turbulent and non-turbulent contributions of a variable

$\mathrm{h} \quad=$ heat source for the conservation of heat

i $\quad=$ co-ordinate index

$\mathrm{j} \quad=$ co-ordinate index normal to $\mathrm{i}$

$\mathrm{k} \quad=$ kinetic energy 


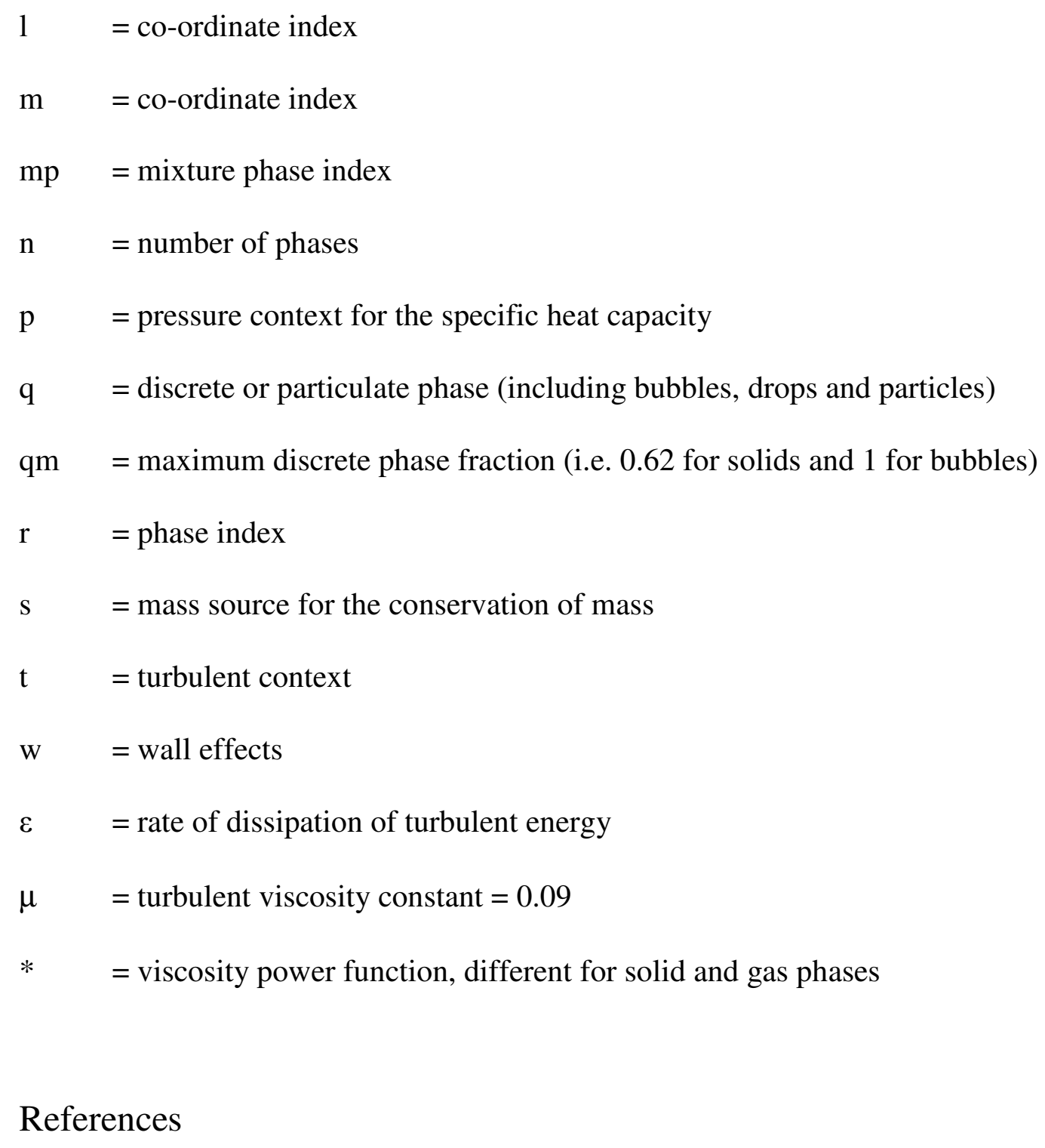

\section{References}

[1] Deckwer, W. -D. Bubble Column Reactors, Jon Wiley and Sons Ltd, Chichester, England, 1992

[2] Joshi, J. B. Computational flow modelling and design of bubble column reactors, Chem. Eng. Sci. 56 (2001) 5893-5933

[3] Torvik, R. and Svendsen, H. F. Modeling of slurry reactors: A fundamental approach, Chem. Eng. Sci. 45(8) (1990) 2325-2332 
[4] Svendsen, H. F. Jakobsen, H. A. and Torvik, R. Local flow structure in internal loop and bubble column reactors, Chem. Eng. Sci. 47(13-14) (1992) 3297-3304

[5] Sokolichin, A. and Eigenberger, G. Gas-liquid flow in bubble columns and loop reactors: Part I. Detailed modelling and numerical simulation, Chem. Eng. Sci. 49(24) (1994) 57355746

[6] Becker, S. Sokolichin, A. and Eigenberger, G. Gas-liquid flow in bubble columns and loop reactors: Part II. Comparisons of detailed experiments and flow simulations, Chem. Eng. Sci. 49(24) (1994) 5747-5762

[7] Sokolichin, A. Eigenberger, G. Lapin, A. and Lüebbert, A. Dynamic numerical simulation of gas-liquid two-phase flows, Chem. Eng. Sci. 52(4) (1997) 611-626

[8] Sokolichin, A. and Eigenberger, G. Applicability of the standard k- $\varepsilon$ turbulence model to the dynamic simulation of bubble columns: Part I. Detailed numerical simulations, Chem. Eng. Sci. 54(13-14) (1999) 2273-2284

[9] Borchers, O. Busch, A. Sokolichin, A. and Eigenberger, G. Application of the standard k- $\varepsilon$ turbulence model to the dynamic simulation of bubble columns. Part II: Comparison of detailed experiments and flow simulations, Chem. Eng. Sci. 54(24) (1999) 5927-5935

[10] Lapin, A. and Lüebbert, A. Numerical simulation of the dynamics of two-phase gas-liquid flows in bubble columns, Chem. Eng. Sci. 49(21) (1994) 3661-3674.

[11] Delnoij, E. Fluid dynamics of gas-liquid bubble columns - a theoretical and experimental study, PhD Thesis, Twente University, The Netherlands, 1998, ISBN 90-36512085

[12] Ranade, V. V. Modeling of turbulent flow in a bubble column reactor, Chem. Eng. Res. and Des. 75A, (1997) 14-23

[13] Sanyal, J. Vásquez, S. Roy, S. and Dudukovic, M. P. Numerical simulation of gas-liquid dynamics in cylindrical bubble column reactors, Chem. Eng. Sci. 54(21) (1999) 5071-5083 
[14] Cartland Glover, G. M., Generalis, S. C. and Thomas, N. H. CFD and Bubble Column Reactors: Simulation and Experiment, Chem. Pap. 54(6) (2000) 361-370

[15] Cartland Glover, G. M., Generalis, S. C. and Thomas, N. H. Dynamic simulations of multiphase flow in bubble columns, Proceedings of the $14^{\text {th }}$ International Congress of Chemical and Process Engineering, CHISA 2000, 27-31 August 2000, Prague, Czech Republic, Lecture G5.5, ISBN 80-86059-30-8

[16] Cartland Glover, G. M., Generalis, S. C. and Thomas, N. H. Three phase flow in bubble columns, $3^{\text {rd }}$ European Congress of Chemical Engineering, Session 16 Multiphase Flows, Posters, $26^{\text {th }}-28^{\text {th }}$ June 2001 , Nuremberg, Germany, (http://www.dechema.de/veranstaltung/ecce/cd/table16.htm)

[17] Degaleesan, S. Fluid dynamic measurements and modelling of liquid mixing in bubble columns. D.Sc. Thesis, Washington University, St Louis, Missouri, USA, 1997

[18] Degaleesan, S. Dudukovic, M. P. and Yan, P. Experimental study of gas-induced liquidflow structures in bubble columns, AIChE J. 47(9) (2001) 1913-1931

[19] Kumar, S. B. Computed tomographic measurements of void fraction and modelling of the flow in bubble columns. PhD Thesis, Florida Atlantic University: Boca Raton, Florida, USA, 1994

[20] Launder, B. E. and Spalding, D. B. The numerical computation of turbulent flows, Comp. Methods in App. Mech. and Eng. 3 (1974) 269-289

[21] Nagata, M. and Busse, F. H. Three-dimensional tertiary motions in a plane shear layer, J. Fluid Mech. 135 (1983) 1-26

[22] Chait, A. and Korpela, S. A. The secondary flow and its stability for natural convection in a tall vertical enclosure, J. Fluid Mech. 200 (1989) 189-216 
[23] Van Den Akker, H. A. Coherent structures in multiphase flows, Powder Tech. 100 (1998) $123-136$

[24] Zuber, N. and Findlay, J. A. Average volumetric concentrations in two-phase flow systems, J. Heat Transfer 87 (1965) 453-468

[25] Ishii, M. and Zuber, N. Drag coefficient and relative velocity in bubbly, droplet and particulate flow, AIChE J. 25 (1979) 843-854

[26] Ishii, M. and Mishima, K. Two-fluid model and hydrodynamic constitutive relations, Nuclear Eng. and Des. 82 (1984) 107-126

[27] Manninen, M. Taivassalo V. and Kallio, S. On the mixture model for multiphase flow, VTT Publications, Paper 288 (1996) IBSN 951-38-4946-5

[28] Fluent Solvers, Fluent Europe Ltd, Sheffield Airport Business Park, Europa Link, Sheffield S9 1XU (www.fluent.co.uk)

[29] FLUENT 5 Users Guide, Fluent Incorporated, Centerra Park, 10 Cavendish Court, Lebanon, NH03766, USA, 1998

[30] Leonard, B. P. A stable and accurate convective modelling procedure based on quadratic upstream interpolation, Comp. Methods in Appl. Mech. and Eng. 19 (1979) 59-98

[31] Patanakar, S. V., Numerical Heat Transfer and Fluid-Flow, Hemisphere Publishing, New York, London, 1980

[32] Barth, T. J. and Jespersen, D. The design and application of upwind schemes on unstructured meshes, Technical Report AIAA-890366, AIAA 27 $7^{\text {th }}$ Aerospace Sciences Meeting, Reno, Nevada, USA, 1989

[33] Vandoormaal, J. P. and Raithby, G. D. Enhancement of the SIMPLE method for predicting incompressible fluid-flows, Num. Heat Transfer 7 (1984) 147-163 
[34] Versteeg, H.K. and Malalasekera, W., An introduction to Computational Fluid Dynamics, Longman Group Ltd, London, England, 1995

\section{Figures}

Fig. 1. Longitudinal plots of vectors of velocity obtain from tracking of a radioactive source at a superficial gas velocity of $2 \mathrm{~cm} \mathrm{~s}^{-1}$ [17];

Fig. 2. Corresponding vector fields obtained from two-dimensional axi-symmetric simulations [13] at two superficial gas velocities; a: $2 \mathrm{~cm} \mathrm{~s}^{-1}$; b: $12 \mathrm{~cm} \mathrm{~s}^{-1}$;

Fig. 3. Vector fields obtained at a superficial gas velocity of $2 \mathrm{~cm} \mathrm{~s}^{-1}$ utilising the $\mathrm{k}-\varepsilon$ turbulence model [15]; A: two-dimensional plane; B: vertical slice from a cylindrical simulation of the bubble column;

Fig. 4. Vectors of velocity $\left(\mathrm{m} \mathrm{s}^{-1}\right)$ obtained from the lateral convection of heat simulations. The scale on the left is for the colour of the vectors for the 50:1 height to width aspect ratio mesh where the turbulence models were different for each case; A: k- $\varepsilon$ turbulence model; B: Reynolds Stresses model with no basic flow profiles; C: Reynolds Stresses model with velocity profile updated after each time-step; 
Fig. 5. Contours of stream function $\left(\mathrm{kg} \mathrm{s}^{-1}\right)$ obtained from the lateral convection of heat simulations. The scale on the left is for the colour of the stream function contours for the 50:1 height to width aspect ratio mesh where the turbulence models were different for each case; A: k$\varepsilon$ turbulence model; B: Reynolds Stresses model with no basic flow profiles; C: Reynolds Stresses model with velocity profile updated after each time-step;

Fig. 6. Time series of the vertical mixture velocity $\left(\mathrm{m} \mathrm{s}^{-1}\right)$ for gas-liquid flow on the column centre line at a height of 2.5 column widths; A1: - ; A2: ---; S1: - ; S2: $\cdots \cdots \cdot \cdot$

Fig. 7. Profile plots of the vertical mixture velocity $\left(\mathrm{m} \mathrm{s}^{-1}\right)$ for gas-liquid flow at a height of 2.5

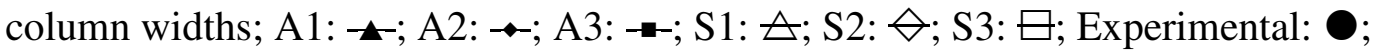

Fig 8. Profile plots of the gas volume fraction (-) for gas-liquid flow at a height of 2.5 column

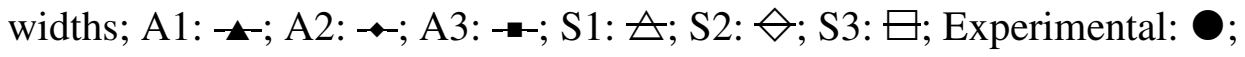

Fig. 9. A1 to A3 field plots at 300 seconds; A: A1 velocity vectors, scale from $0 \mathrm{~m} \mathrm{~s}^{-1}$ for small vectors to $0.5 \mathrm{~m} \mathrm{~s}^{-1}$ for large vectors; B: A1 gas fractions, scale from 0 for black contours to 0.15 for light grey contours; $\mathrm{C}$ : A2 velocity vectors, scale from $0 \mathrm{~m} \mathrm{~s}^{-1}$ for small vectors to $0.5 \mathrm{~m} \mathrm{~s}^{-1}$ for large vectors; D: A2 gas fractions, scale from 0 for black contours to 0.15 for light grey contours; E: A3 velocity vectors, scale from $0 \mathrm{~m} \mathrm{~s}^{-1}$ for small vectors to $1.0 \mathrm{~m} \mathrm{~s}^{-1}$ for large vectors; F: A3 gas fractions, scale from 0 for black contours to 0.15 for light grey contours; 
Fig. 10. S1 to S3 field plots at 300 seconds; A: S1 velocity vectors, scale from $0 \mathrm{~m} \mathrm{~s}^{-1}$ for small vectors to $0.4 \mathrm{~m} \mathrm{~s}^{-1}$ for large vectors; B: S1 gas fractions, scale from 0 for black contours to 0.5 for light grey contours; C: S2 velocity vectors, scale from $0 \mathrm{~m} \mathrm{~s}^{-1}$ for small vectors to $0.5 \mathrm{~m} \mathrm{~s}^{-1}$ for large vectors; D: S2 gas fractions, scale from 0 for black contours to 0.5 for light grey contours; E: S3 velocity vectors, scale from $0 \mathrm{~m} \mathrm{~s}^{-1}$ for small vectors to $0.6 \mathrm{~m} \mathrm{~s}^{-1}$ for large vectors; $\mathrm{F}$ : S2 gas fractions, scale from 0 for black contours to 0.5 for light grey contours;

Table 1 Lateral convection case specifications

Table 2 Gas-liquid flow case specifications 

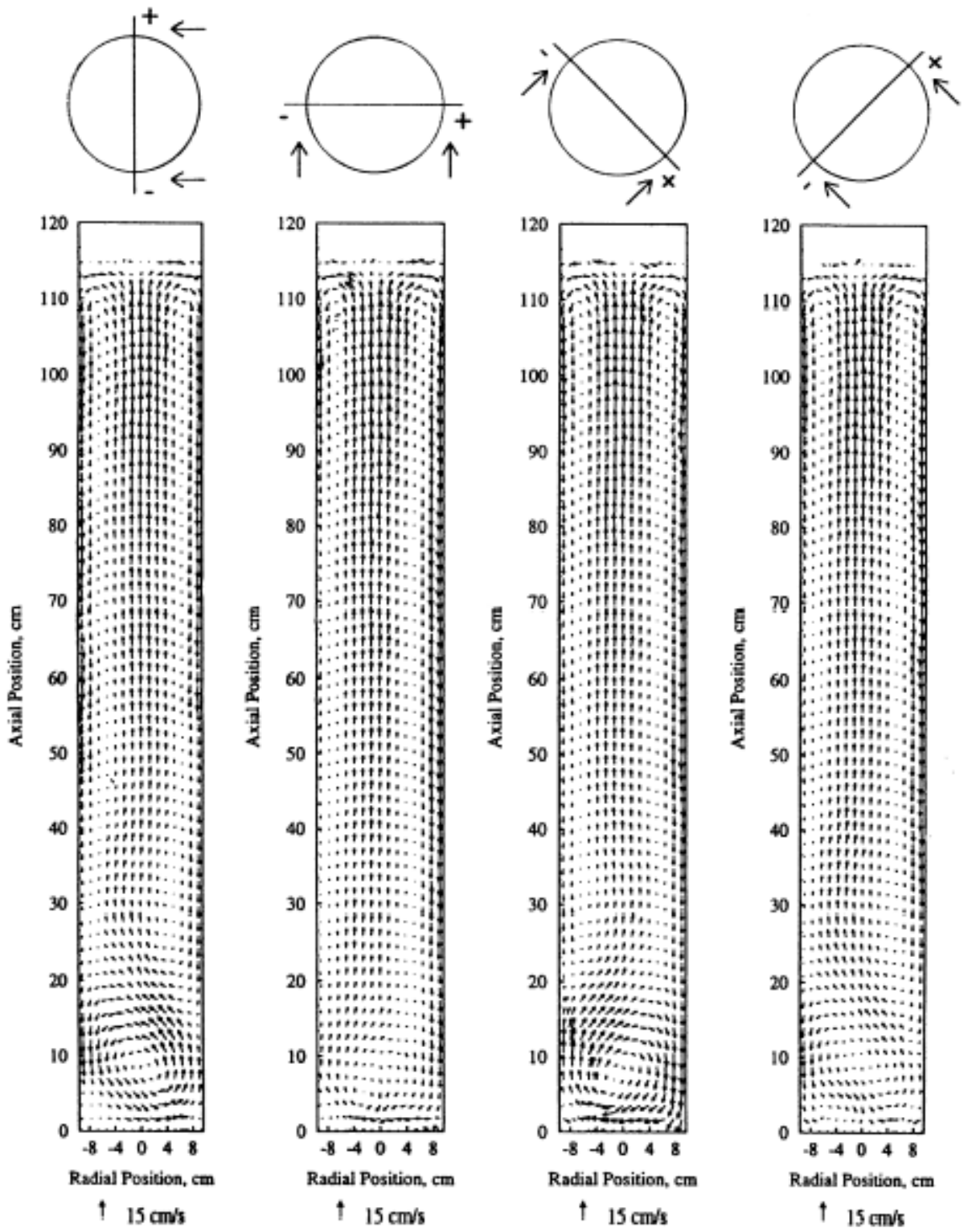

(a)

(b)

(c)

(d)

Fig. 1. 


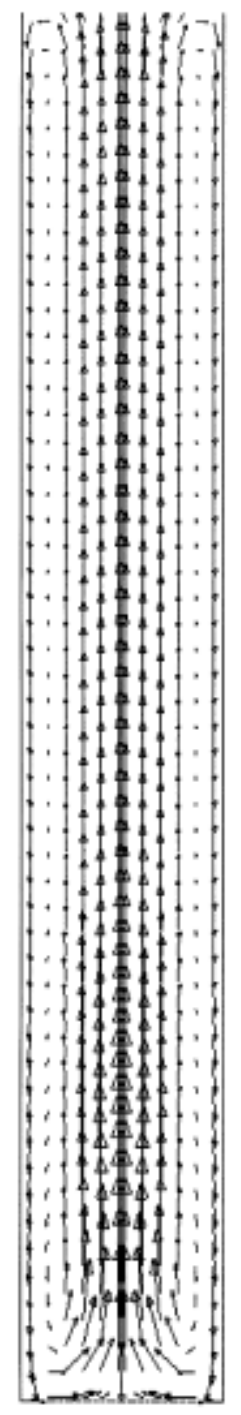

(a)

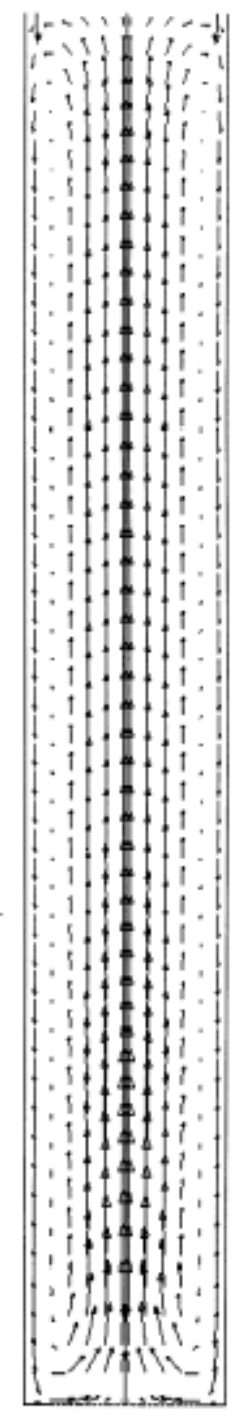

(b)

Fig. 2. 


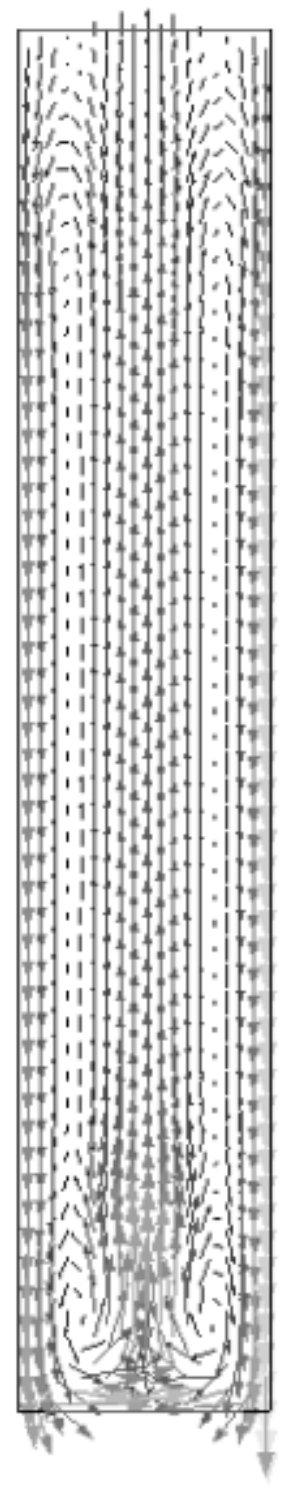

A

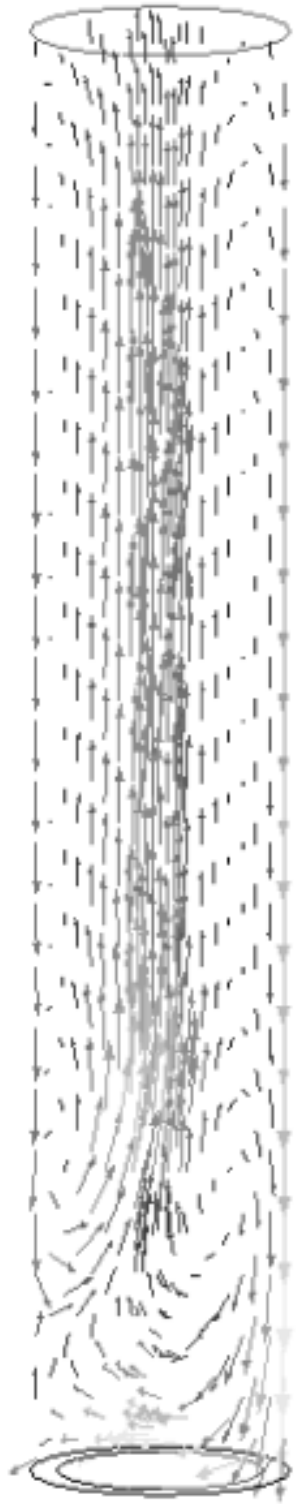

B

Fig. 3. 


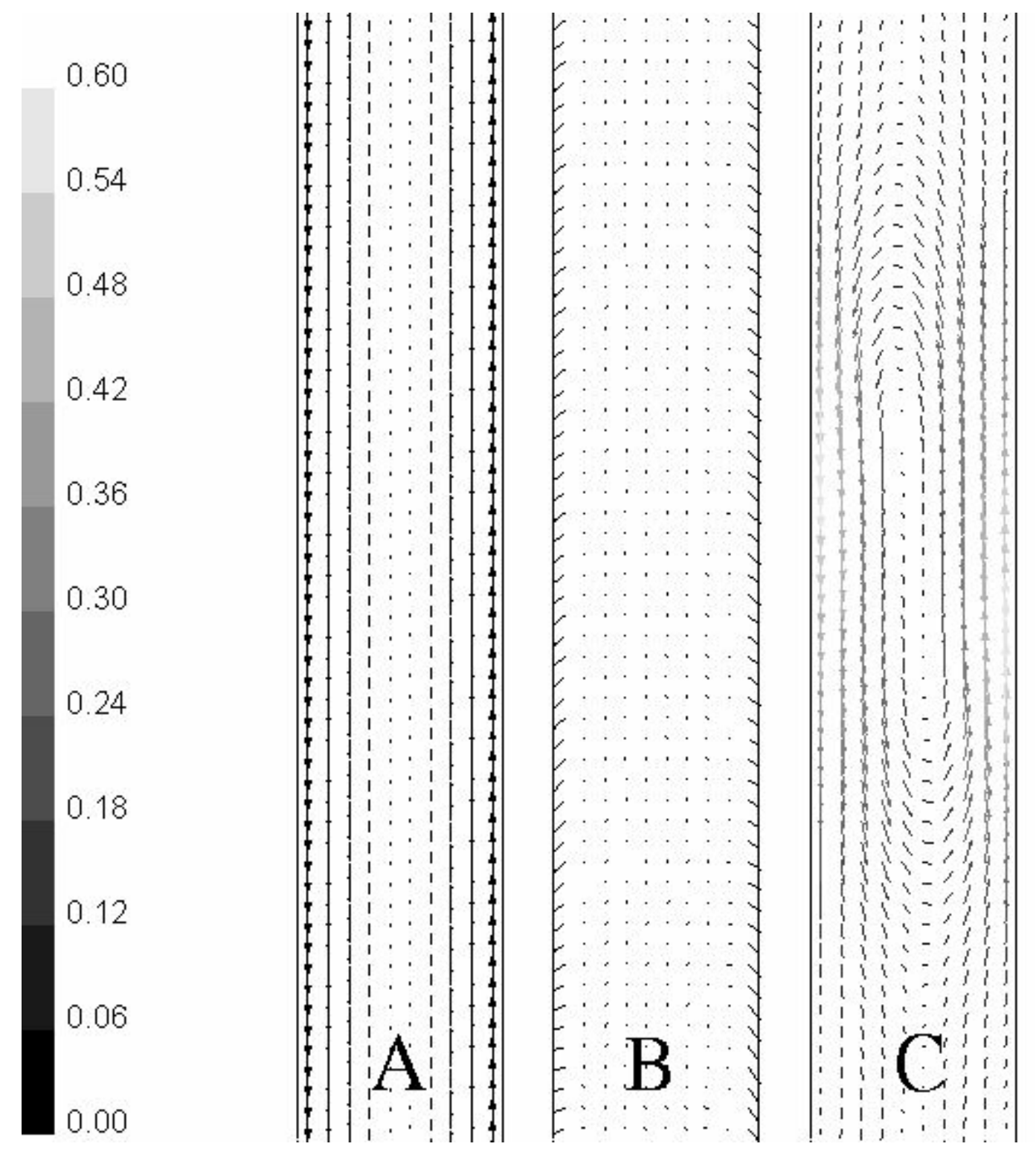

Fig. 4. 

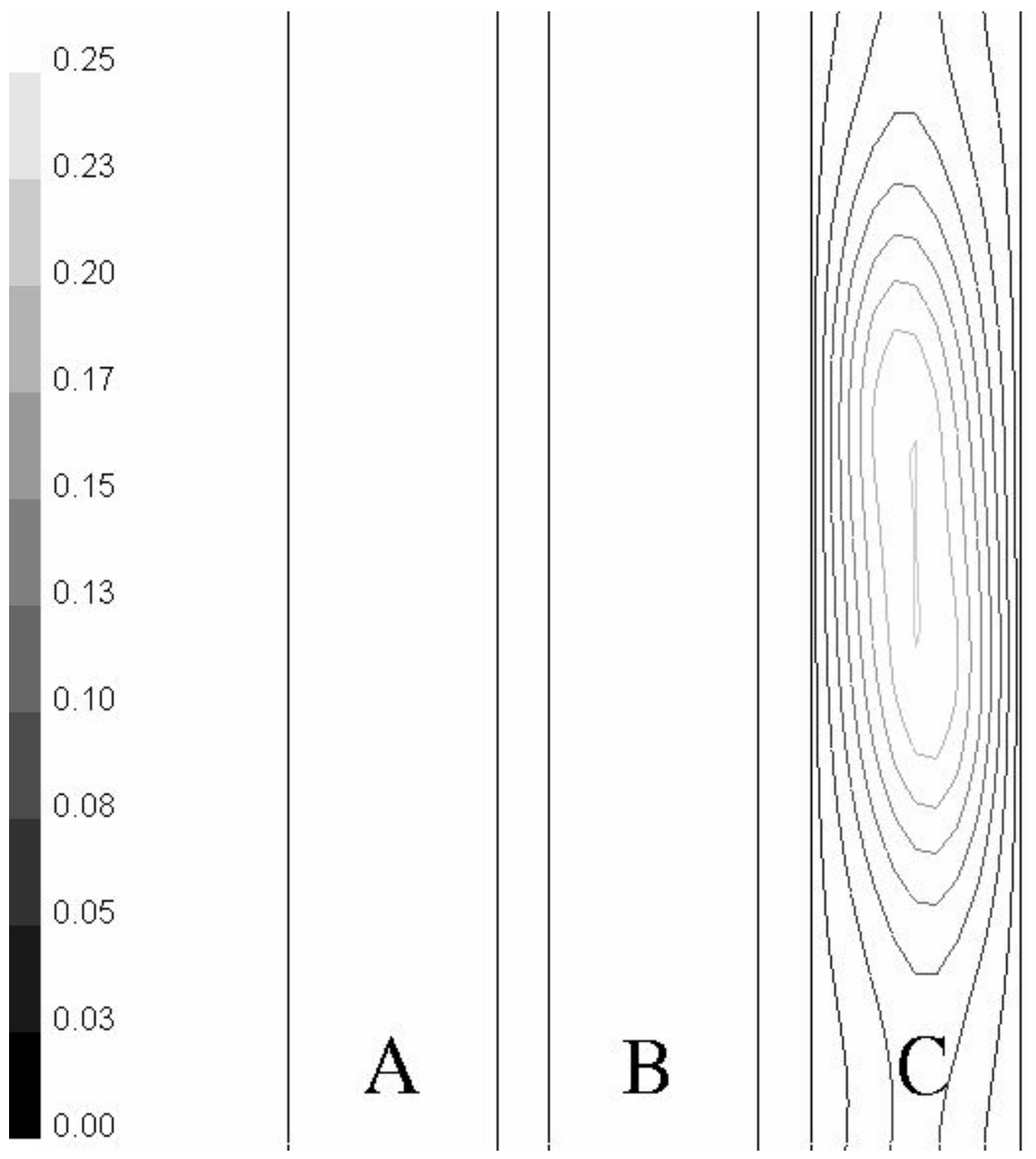

Fig. 5. 


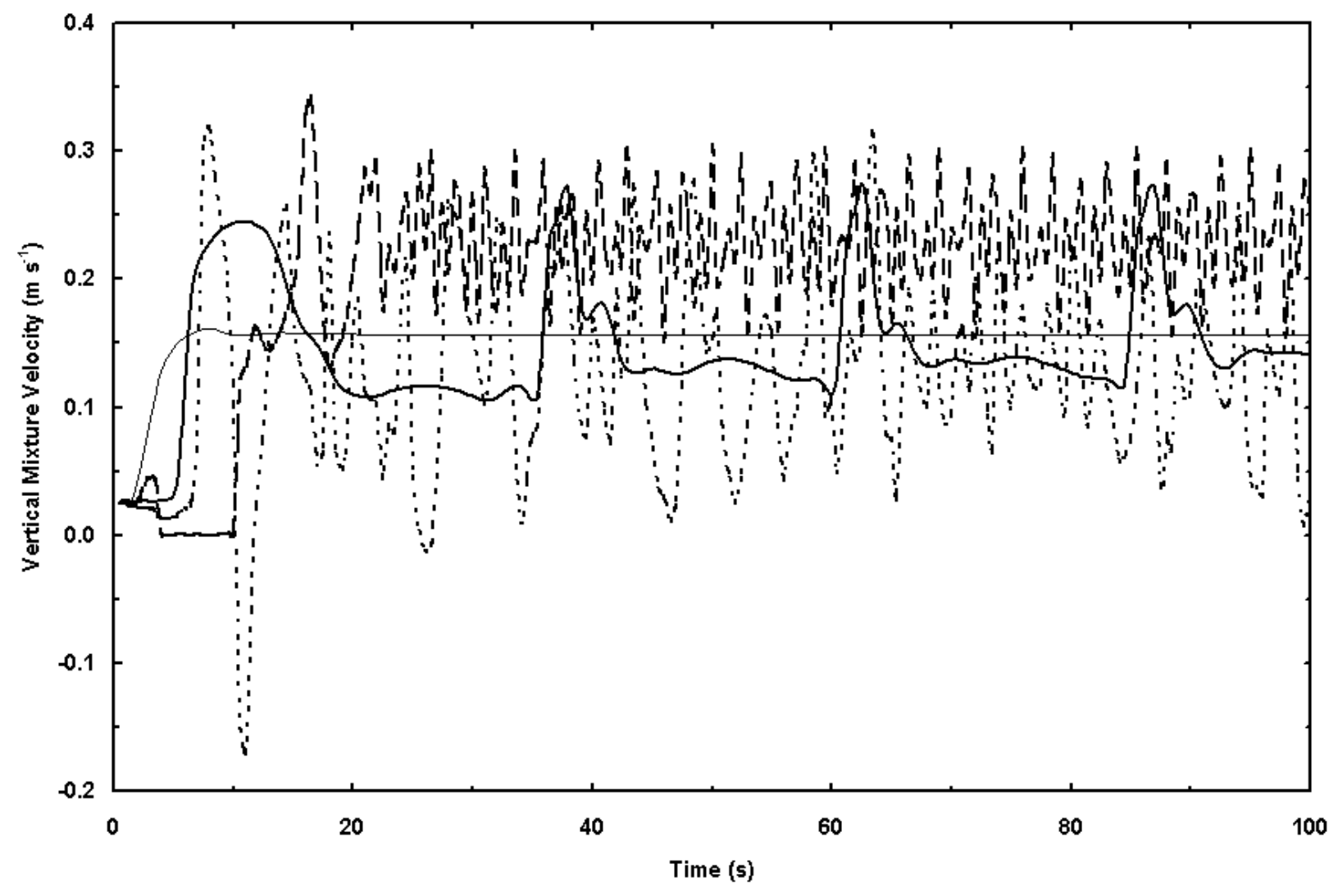

Fig. 6. 


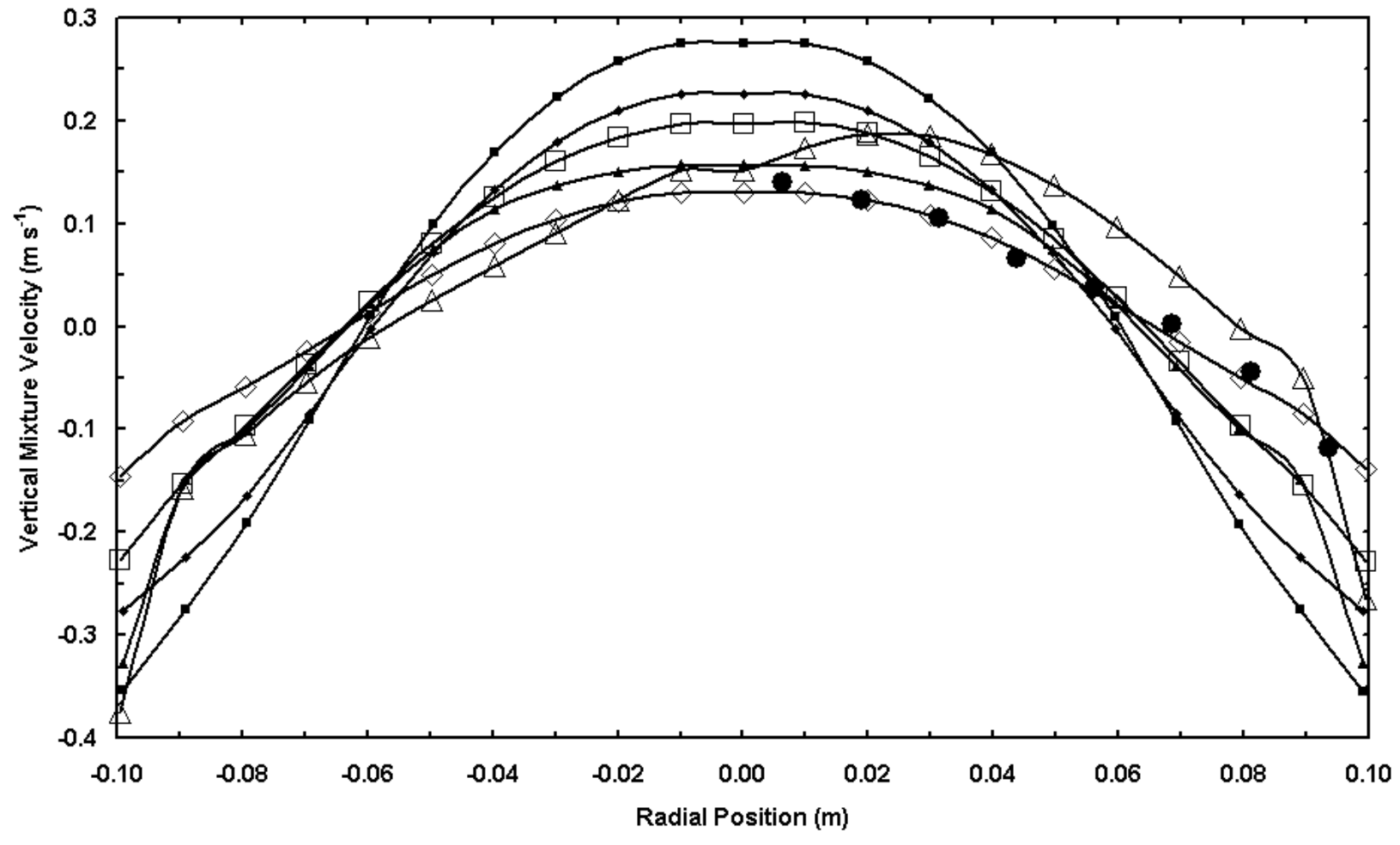

Fig. 7. 


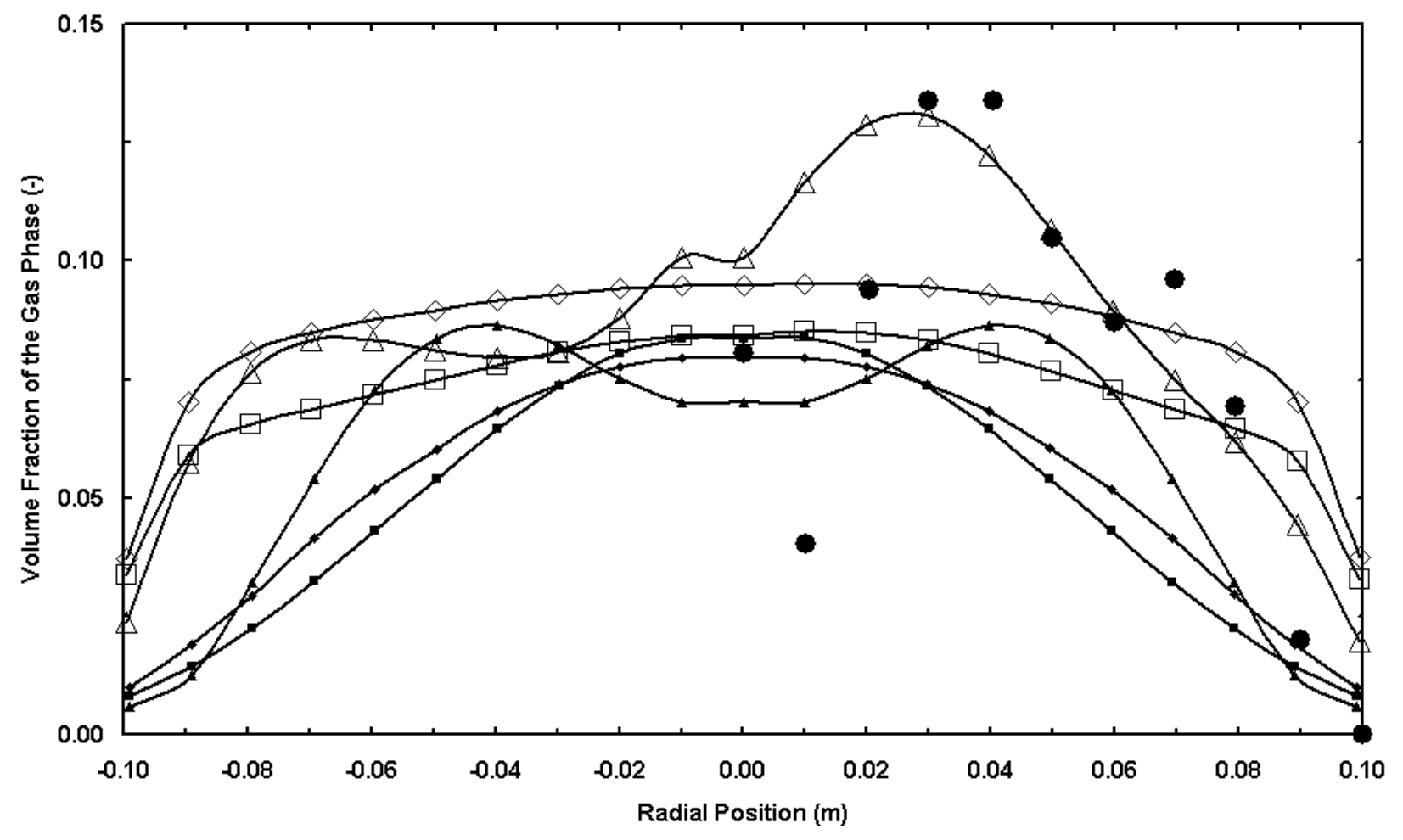

Fig. 8 . 


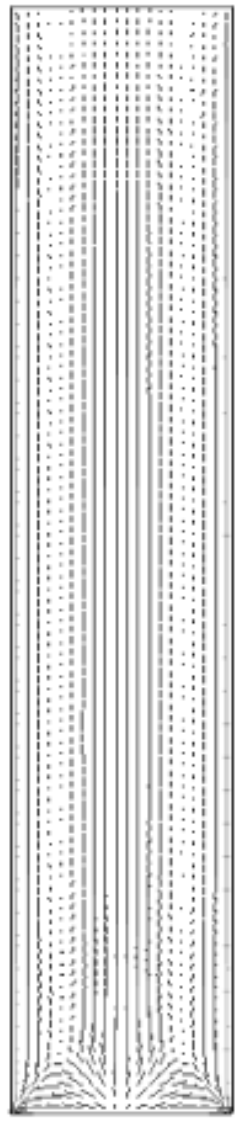

A

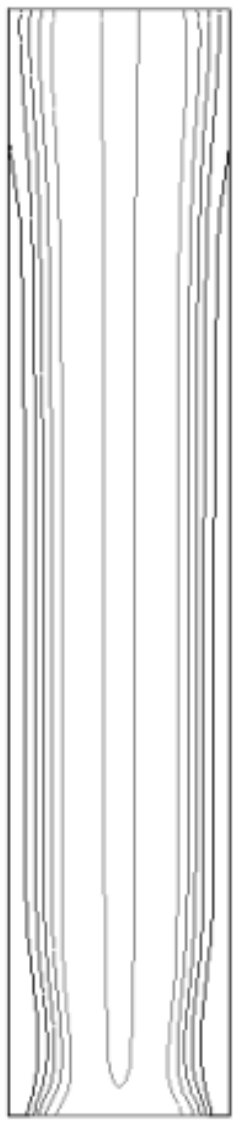

B

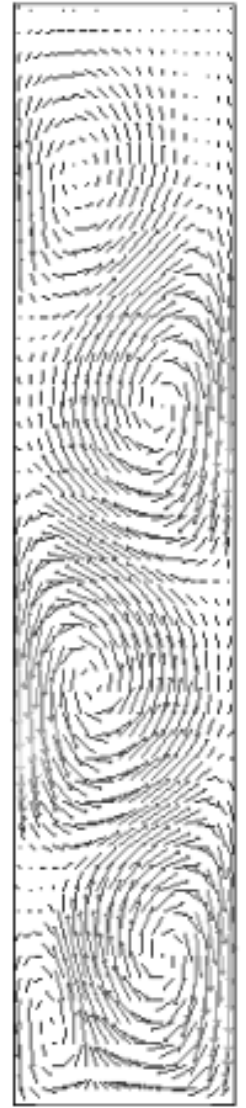

C

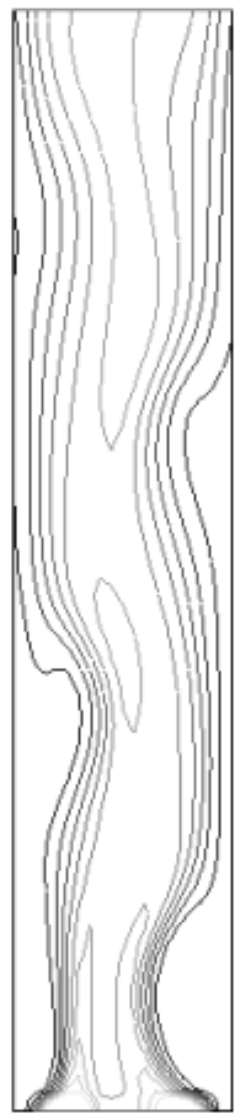

D

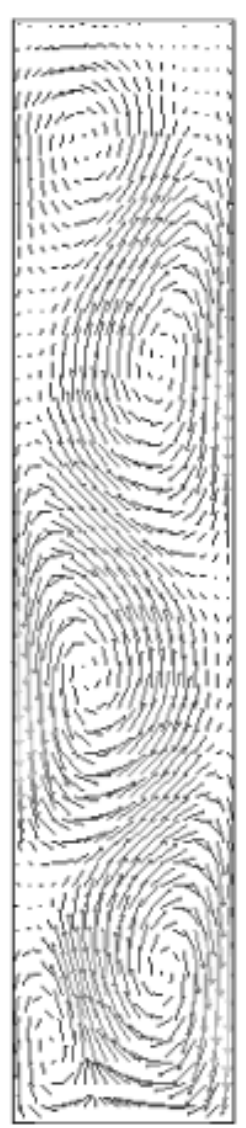

E

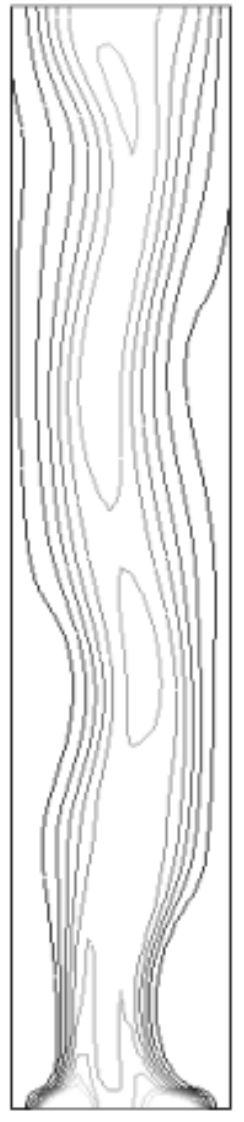

F

Fig. 9. 

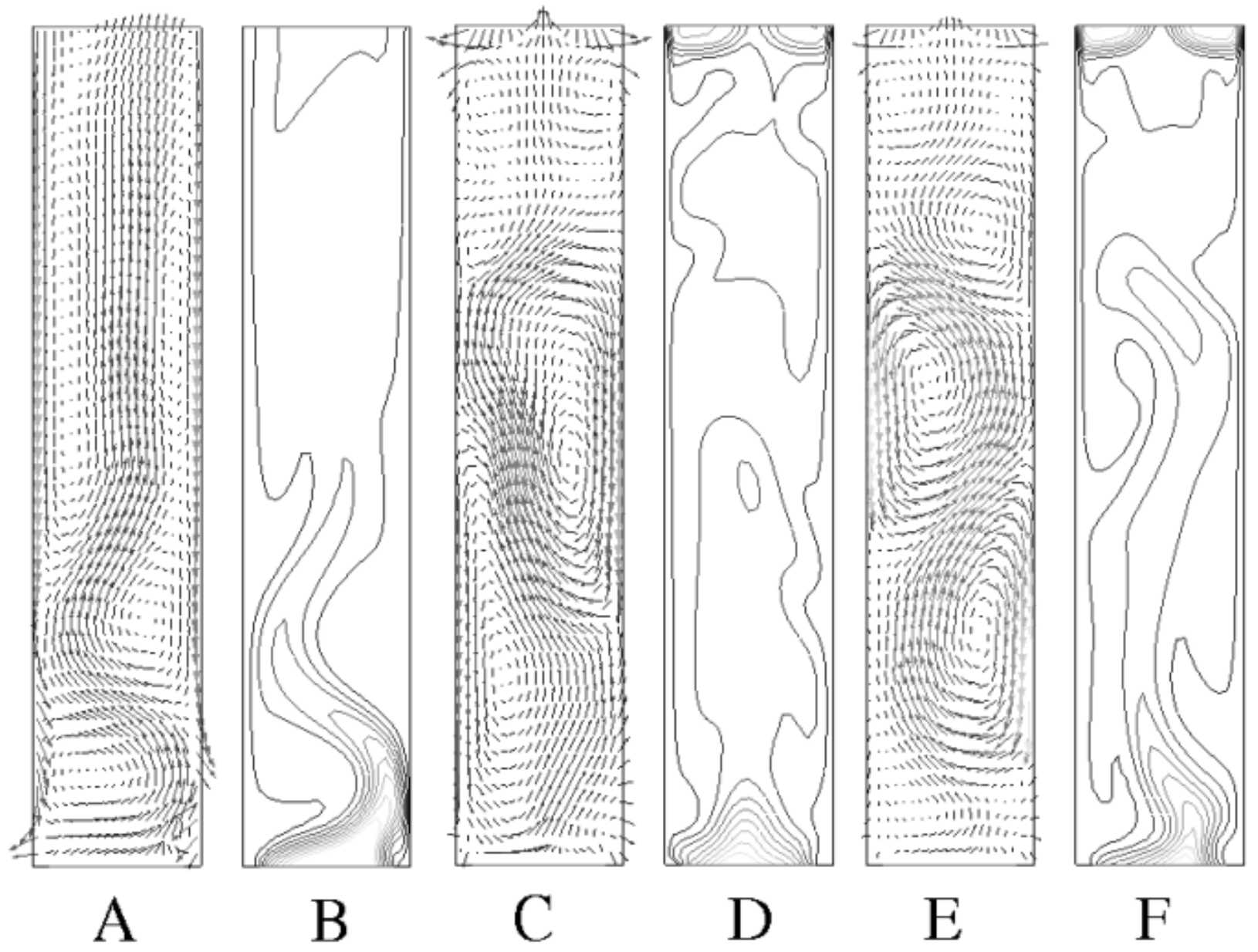

Fig. 10. 
Table 1

\begin{tabular}{|c|c|c|c|c|c|c|}
\hline \multirow[t]{2}{*}{ Case } & \multirow[t]{2}{*}{ Phenomena } & \multirow[t]{2}{*}{$\begin{array}{c}\text { Flow } \\
\text { Equation }\end{array}$} & \multirow[t]{2}{*}{$\begin{array}{c}\text { Turbulence } \\
\text { Model }\end{array}$} & \multicolumn{3}{|c|}{ Temperature Condition (K) } \\
\hline & & & & Left Wall & Fluid/Top/Base & Right Wall \\
\hline A & $\begin{array}{c}\text { Lateral } \\
\text { Convection } \\
\text { Lateral }\end{array}$ & $\begin{array}{l}\text { Energy } \\
\text { Equation } \\
\text { Eneroy }\end{array}$ & $\begin{array}{l}\text { k-e } \\
\text { turbulence } \\
\text { Revnolds }\end{array}$ & 300 & 305 & 310 \\
\hline $\mathrm{B}$ & Convection & Equation & $\begin{array}{l}\text { stresses } \\
\text { Reynolds } \\
\text { stresses } \\
\text { with a } \\
\text { laminar }\end{array}$ & 300 & 305 & 310 \\
\hline $\mathrm{C}$ & $\begin{array}{c}\text { Lateral } \\
\text { Convection }\end{array}$ & $\begin{array}{l}\text { Energy } \\
\text { Equation }\end{array}$ & $\begin{array}{l}\text { flow } \\
\text { profile }\end{array}$ & 300 & 305 & 310 \\
\hline
\end{tabular}


Table 2

\begin{tabular}{|c|c|c|c|c|c|c|c|}
\hline & & A1 & $\mathrm{A} 2$ & A3 & $\mathrm{S} 1$ & $\mathrm{~S} 2$ & S3 \\
\hline \multicolumn{2}{|c|}{ Algebraic Slip Mixture Model } & Yes & Yes & Yes & - & - & - \\
\hline \multicolumn{2}{|c|}{ Modified Scalar Mixture Model } & - & - & - & Yes & Yes & Yes \\
\hline \multicolumn{2}{|c|}{ k-e turbulence } & Yes & - & - & Yes & - & - \\
\hline Reynol & s Stresses & - & Yes & - & - & Yes & - \\
\hline Reynolds Stress & s with flow profile & - & - & Yes & - & - & Yes \\
\hline \multirow[t]{3}{*}{ Gas Inlet } & Velocity (m s-1) & 0.032 & 0.032 & 0.032 & 0.032 & 0.032 & 0.032 \\
\hline & Defintion & Fraction & Fraction & Fraction & Flux & Flux & Flux \\
\hline & Value & 1 & 1 & 1 & 0.6 & 0.6 & 0.6 \\
\hline \multirow[t]{2}{*}{ Liquid Surface } & Definition & Fraction & Fraction & Fraction & Flux & Flux & Flux \\
\hline & Value & 0 & 0 & 0 & 0 & 0 & 0 \\
\hline \multirow[t]{2}{*}{ Walls } & Definition & Fraction & Fraction & Fraction & No flux & No flux & No flux \\
\hline & Value & 0 & 0 & 0 & 0 & 0 & 0 \\
\hline
\end{tabular}

